\title{
Clinical Significance of Preoperative Virtual Colonoscopy for Evaluation of the Proximal Colon in Patient With Obstructive Colorectal Cancer
}

\author{
Jae-Hyuk Heo ${ }^{1}$, Chun-Geun Ryu ${ }^{1}$, Eun-Joo Jung ${ }^{1}$, Jin-Hee Paik ${ }^{1}$, Dae-Yong Hwang ${ }^{1,2}$ \\ ${ }^{1}$ Department of Surgery, Colorectal Cancer Center, Konkuk University Medical Center, Seoul; ${ }^{2}$ Department of Surgery, Konkuk University \\ School of Medicine, Seoul, Korea
}

Purpose: Virtual colonoscopy is the most recently developed tool for detecting colorectal cancers and polyps, but its effectiveness is limited. In our study, we compared the result of preoperative virtual colonoscopy to result of preoperative and postoperative colonoscopy. We evaluated also the accuracy of preoperative virtual colonoscopy in patients who had obstructive colorectal cancer that did not allow passage of a colonoscope.

Methods: A total of 164 patients who had undergone preoperative virtual colonoscopy and curative surgery after the diagnosis of a colorectal adenocarcinoma between November 2008 and August 2013 were pooled. We compared the result of conventional colonoscopy with that of virtual colonoscopy in the nonobstructive group and the results of preoperative virtual colonoscopy with that of postoperative colonoscopy performed at 6 months after surgery in the obstructive group. Results: Of the 164 patients, 108 were male and 56 were female patients. The mean age was 62.7 years. The average sensitivity, specificity, and accuracy of virtual colonoscopy for all patients were $31.0 \%, 67.2 \%$, and $43.8 \%$, respectively. In the nonobstructive group, the average sensitivity, specificity, and accuracy were $36.6 \%, 66.2 \%$, and $48.0 \%$, respectively, whereas in the obstructive group, they were $2 \%, 72.4 \%$, and $25.4 \%$. Synchronous cancer was detected via virtual colonoscopy in 4 of the 164 patients.

Conclusion: Virtual colonoscopy may not be an effective method for the detection of proximal colon polyps, but it can be helpful in determining the therapeutic plan when its results are correlated with the results of other studies.

Keywords: Colorectal neoplasms; Colonoscopy; Computed tomographic colonography; Colonic polyps

\section{INTRODUCTION}

Colorectal cancer is the third most common cancer in men and the second most common cancer in women worldwide. In Asia, colorectal cancer is the fourth most common cancer in men and the fifth most common cancer in women. Especially, the incidence of colorectal cancer is higher in East Asian countries than

Received: May 8,2017 - Accepted: June 12, 2017

Correspondence to: Dae-Yong Hwang, M.D.

Department of Surgery, Colorectal Cancer Center, Konkuk University Medical Center, Konkuk University School of Medicine, 120-1 Neungdong-ro,

Gwangjin-gu, Seoul 05030, Korea

Tel: +82-2-2030-5111, Fax: +82-2-2030-5112

E-mail: hwangcrc@kuh.ac.kr

(c) 2017 The Korean Society of Coloproctology

This is an open-access article distributed under the terms of the Creative Commons Attribution NonCommercial License (http://creativecommons.org/licenses/by-nc/4.0) which permits unrestricted noncommercial use, distribution, and reproduction in any medium, provided the original work is properly cited. in all Asian countries [1]. In Korea, the prevalence of colorectal cancer is the second highest after that of stomach cancer, and the incidence rate of colorectal cancer is the third highest after those of thyroid cancer and stomach cancer. Also, the incidence of colorectal cancer is increasing, and because colorectal cancer develops from a precursor adenomatous polyp, the detection and removal of polyps are important in preventing colorectal cancer [2].

In colorectal cancer evaluation, a proximal colon evaluation is necessary. The incidence of coexisting polyps has been reported to be about $27 \%-55 \%$ and the incidence of synchronous cancer to be about 1.8\%-19\% [3]. Therefore, the National Comprehensive Cancer Network (NCCN) guidelines have suggested a complete colonoscopy preoperatively. However, in patients who have obstructive colorectal cancer, the colonoscope cannot pass into the proximal colon, so the proximal colon cannot be evaluated. In these cases, virtual colonoscopy may be helpful [4]. However, the 
clinical significance of virtual colonoscopy has not yet been established. Therefore, the aim of this study is to evaluate the clinical usefulness of preoperative virtual colonoscopy for examining the proximal colon in patients with colorectal cancer.

\section{METHODS}

Of the patients who were scheduled for a curative operation based on the diagnosis of a colorectal adenocarcinoma, a total of 164 patients in whom preoperative virtual colonoscopy had been performed between November 2008 and August 2013 were pooled. Patients who needed an emergent operation for colon obstruction were excluded. The 164 selected patients were subdivided into 2 groups: the nonobstructive (137 patients) group and the obstructive group (27 patients), where preoperative colon obstruction was defined as obstruction that prevented the colonoscope from passing into the proximal colon from the primary tumor. In the obstructive group, patients who received a right hemicolectomy were excluded. This is the reason we could not evaluate the proximal colon postoperatively after curative surgery. In the nonobstructive group, the results of preoperative complete colonoscopy

Table 1. Patients' characteristics

\begin{tabular}{|c|c|c|c|}
\hline \multirow[b]{2}{*}{ Characteristic } & \multicolumn{2}{|c|}{ Group } & \multirow[b]{2}{*}{ Total } \\
\hline & $\begin{array}{l}\text { Nonobstructive } \\
\quad(n=137)\end{array}$ & $\begin{array}{l}\text { Obstructive }^{\mathrm{a}} \\
(\mathrm{n}=27)\end{array}$ & \\
\hline Sex, male : female & $92: 45$ & $16: 11$ & $108: 56$ \\
\hline Age (yr) & $\begin{array}{c}64.1 \pm 12.3 \\
(40-87)\end{array}$ & $\begin{array}{c}60.5 \pm 15.1 \\
(34-85)\end{array}$ & $\begin{array}{c}62.7 \pm 16.2 \\
(34-87)\end{array}$ \\
\hline \multicolumn{4}{|c|}{ Location of the tumor } \\
\hline Cecum & $2(1.5)$ & $0(0)$ & $2(1.2)$ \\
\hline Ascending & $13(9.5)$ & $0(0)$ & $13(7.9)$ \\
\hline Hepatic flexure & $1(0.7)$ & $0(0)$ & $1(0.6)$ \\
\hline Transverse & $6(4.4)$ & $1(3.7)$ & $7(4.3)$ \\
\hline Splenic flexure & $1(0.7)$ & $3(11.1)$ & $4(2.4)$ \\
\hline Descending & $1(0.7)$ & $1(3.7)$ & $2(1.2)$ \\
\hline Sigmoid & $37(27.0)$ & $9(33.3)$ & $46(28.0)$ \\
\hline Rectosigmoid & $41(29.9)$ & $12(44.4)$ & 53 (32.3) \\
\hline Rectum & $35(25.5)$ & $1(3.7)$ & $36(22.0)$ \\
\hline \multicolumn{4}{|l|}{ TNM stage } \\
\hline 0 & $10(7.3)$ & $0(0)$ & $10(6.1)$ \\
\hline । & $37(27.0)$ & $0(0)$ & 37 (22.6) \\
\hline$\|$ & 43 (31.4) & $17(63.0)$ & 60 (36.6) \\
\hline III & $37(27.0)$ & $10(37.0)$ & $47(28.7)$ \\
\hline IV & $10(7.3)$ & $0(0)$ & $10(6.1)$ \\
\hline
\end{tabular}

Values are presented as mean \pm standard deviation (range) or number (\%). abstructive group means that the colonoscope could not pass into the proximal colon from the primary tumor. were compared with those of preoperative virtual colonoscopy. In the obstructive group, the results of preoperative virtual colonoscopy were compared with those of complete postoperative colonoscopy performed within 6 months after curative surgery.

For virtual colonoscopy, mechanical bowel preparation was essential. The method of administering polyethylene glycol (PEG) was as follows: a total $4 \mathrm{~L}$ of PEG was taken 12 hours before virtual colonoscopy. In particular, in patients with preoperative colon obstruction, bowel preparation was performed under close monitoring of defecation. The fasting status was maintained for at least 12 hours. Abdomino-pelvic computed tomography (CT) was performed using a 64-channel multidetector CT scanner (LightSpeed VCT, GE Healthcare, Chicago, IL, USA). An automatic inflator with $\mathrm{CO}_{2}(6 \mathrm{~L})$ was used to create the pneumo-colon. The virtual colonoscopic image was reconstructed through the use of software (Rapidia, version 2.8, Infinitt Healthcare, Seoul, Korea).

\section{RESULTS}

A total of 164 patients were enrolled, including 108 men and 56 women. The mean age was 62.7 years (range, $34-87$ years). Preoperative obstruction was found in 27 patients (16.4\%). Most of the primary tumors were located in the sigmoid and the rectosigmoid colon. In the nonobstructive group, the tumor was mainly located in the sigmoid and the rectosigmoid colon in 78 patients (56.9\%) and in the rectum in 35 patients $(25.5 \%)$. In the obstructive group, the tumor was located in the sigmoid and the rectosigmoid colon in 21 patients $(77.7 \%)$. The distribution of the TNM stage is shown in Table 1 . The most commonly performed operations were a low anterior resection (71 patients, 43.3\%) and an anterior resection (51 patients, 31.1\%) (Table 2).

Of the 161 polyps detected by using preoperative colonoscopy in the nonobstructive group, 59 (36.6\%) were also detected by using virtual colonoscopy (Table 3 ). Of the 76 polyps with sizes

Table 2. Type of operation

\begin{tabular}{lccc}
\hline \multirow{2}{*}{ Variable } & \multicolumn{2}{c}{ Group } & \\
\cline { 2 - 3 } & $\begin{array}{c}\text { Nonobstructive } \\
(\mathrm{n}=137)\end{array}$ & $\begin{array}{c}\text { Obstructive } \\
(\mathrm{n}=27)\end{array}$ & Total \\
\hline Right hemicolectomy & $22(16.1)$ & $0(0)$ & $22(13.4)$ \\
Transverse colectomy & $2(1.5)$ & $1(3.7)$ & $3(1.8)$ \\
Left hemicolectomy & $2(1.5)$ & $4(14.8)$ & $6(3.7)$ \\
Anterior resection & $40(29.2)$ & $11(40.7)$ & $51(31.1)$ \\
Low anterior resection & $61(44.5)$ & $10(37.0)$ & $71(43.3)$ \\
Abdominoperineal resection & $9(6.6)$ & $1(3.7)$ & $10(6.1)$ \\
Total colectomy & $1(0.7)$ & $0(0)$ & $1(0.6)$ \\
\hline
\end{tabular}

Values are presented as number (\%).

${ }^{\mathrm{a}} \mathrm{A}$ total colectomy was performed on patients with rectosigmoid colon cancer with multiple high-grade dysplasia polyps at the ascending colon and the rectum. 


\section{Coloproctology he-tink Heoctil}

Table 3. Polyp detection patterns according to the diagnostic tool

\begin{tabular}{lccc}
\hline Group & $\begin{array}{c}\text { Preoperative } \\
\text { colonoscopy }\end{array}$ & $\begin{array}{c}\text { Virtual } \\
\text { colonoscopy }\end{array}$ & $\begin{array}{c}\text { Postoperative } \\
\text { colonoscopy }\end{array}$ \\
\hline $\begin{array}{l}\text { Nonobstructive group } \\
\text { For all polyps }\end{array}$ & 161 & $59(36.6)$ & - \\
$\quad$ For polyps $\geq 6 \mathrm{~mm}$ & 76 & $45(59.2)$ & - \\
Obstructive group & & & \\
$\quad$ For all polyps & - & $5(11.1)$ & 45 \\
For polyps $\geq 6 \mathrm{~mm}$ & - & $5(25.0)$ & 20 \\
\hline
\end{tabular}

Values are presented as number or number (\%).

greater than or equal to $6 \mathrm{~mm}$ detected by using preoperative colonoscopy, 45 (59.2\%) were also detected by using virtual colonoscopy. Of the 45 polyps detected by using postoperative colonoscopy in the obstructive group, $5(11.1 \%)$ were also detected by using virtual colonoscopy. Of the 20 polyps ( $\geq 6 \mathrm{~mm}$ ) detected by using postoperative colonoscopy in the obstructive group, 5 $(25.0 \%)$ were also detected by using virtual colonoscopy. The detection rate of polyps with sizes $\geq 6 \mathrm{~mm}$ was higher than that of all polyps in both groups.

The sensitivity, specificity, and accuracy for polyp detection by using virtual colonoscopy are shown in Table 4 . For all polyps, in the nonobstructive group, the sensitivity was $36.6 \%$, the specificity was $66.2 \%$, and the accuracy was $48 \%$. In the obstructive group, the sensitivity was $11.2 \%$, the specificity was $72.4 \%$, and the accuracy was $25.4 \%$. For polyps with sizes larger than or equal to $6 \mathrm{~mm}$, the accuracy of polyp detection was $63.7 \%$ in the nonobstructive group and $44.1 \%$ in the obstructive group. In the obstructive group, synchronous cancer was detected by using virtual colonoscopy in 4 patients (14.8\%). For 2 patients, the operative plan was changed due to virtual colonoscopic findings. The proximal mass was not far from the distal mass, so the proximal mass could be fully included in the resection margin without changing the originally planned operation. The operations performed were an abdominoperineal resection and a left hemicolectomy.

In a 52-year-old female patient, the primary cancer was located at the rectosigmoid junction, and the operative plan was to perform a lower anterior resection. However, cecal cancer was suspected on virtual colonoscopy findings and an uptake of Fluorine-18 fluorodeoxyglucose in the cecum was seen on positron emission tomography (PET)-CT. Therefore, we performed a lower anterior resection and right hemicolectomy. The final pathological diagnosis of the cecal mass was a well-differentiated, T1N0M0, stage I adenocarcinoma.

A 34-year-old female patient was scheduled for surgery on a distal sigmoid colon cancer found on conventional colonoscopy, but a tumor in the proximal sigmoid colon was found on virtual colonoscopy. Also, based on PET-CT findings, another malignancy in the proximal sigmoid colon was suspected. According to the clinical information, the operative plan was changed to an extended
Table 4. Average sensitivity, specificity, and accuracy of polyp detection

\begin{tabular}{lccc}
\hline \multirow{2}{*}{ Polyp } & \multicolumn{2}{c}{ Group } & \multirow{2}{*}{ Total } \\
\cline { 2 - 3 } & Nonobstructive & Obstructive group & \\
\hline For all polyps & & & \\
Sensitivity (\%) & 36.6 & 11.2 & 31.0 \\
\hline Specificity (\%) & 66.2 & 72.4 & 67.2 \\
\hline Accuracy (\%) & 48.0 & 25.4 & 43.8 \\
For polyps $\geq 6$ mm & & & \\
Sensitivity (\%) & 59.2 & 20.0 & 52.8 \\
Specificity (\%) & 37.3 & 71.4 & 67.8 \\
Accuracy (\%) & 63.7 & 44.1 & 60.4 \\
\hline
\end{tabular}

anterior resection. The final pathological diagnosis of the proximal colon mass was an adenocarcinoma.

\section{DISCUSSION}

In this study, the accuracy of polyp detection for virtual colonoscopy was $48.0 \%$ in the nonobstructive group and $25.4 \%$ in the obstructive group. Even though the detection rate of virtual colonoscopy was not high enough, in some patients, the surgical plan was changed based on the result of virtual colonoscopy.

In colorectal cancer patients, the incidence of synchronous colorectal cancer has been reported to be about $1.8 \%-19 \%$ at the time of the diagnosis of colorectal cancer [3]. Therefore, a complete colonoscopy of the entire colon is very important before surgery, and this process of work up is also recommended in the NCCN guidelines [5]. However, in patients with obstructive colorectal cancer, which means that colonoscope cannot pass into the proximal colon, a complete colonoscopy may not be available. In the past, a barium enema was considered as a way to overcome this limitation. The disadvantages of a barium enema include the risk of colon perforation and problems caused by barium remaining in the proximal colon during surgery. With the development of the imaging modality, virtual colonoscopy has been suggested as a possible alternative $[4,6]$.

Virtual colonoscopy has many advantages. Compared with colonoscopy, the procedure is faster, it provides more physical comfort, sedation is not needed, it is less painful, and it is a less difficult examination [7-9]. In addition, virtual colonoscopy is an imaging tool used in combination with CT. Therefore, it has the advantage of $\mathrm{CT}$, which can evaluate the extracolonic findings simultaneously [10]. Due to these advantages, the clinical information can be viewed comprehensively. On the other hand, virtual colonoscopy has certain disadvantages. Like the barium enema, the possibility of false positive results is present because of residual fecal material, haustral folds, the impression of organs, or normal variations of the ileocecal valve $[11,12]$. However, through 
the use of imaging combined with CT, these drawbacks can be overcome. Other disadvantages include radiation hazard and high cost [12].

In colorectal cancer, virtual colonoscopy can be used for the evaluation of colonic polyps and synchronous colorectal cancer. In the literature, the sensitivity of virtual colonoscopy for the detection of adenomatous polyps varies from about $45 \%$ to $97 \%$ [5]. However, in our study, the sensitivity for the detection of polyps by using virtual colonoscopy was relatively low, being $36.6 \%$ in the nonobstructive group and $11.2 \%$ in the obstructive group. This difference probably originated from the other studies having different aims and different patient groups. The studies that assessed the sensitivity and the specificity of virtual colonoscopy enrolled a high number of normal or asymptomatic patients who had undergone a virtual colonoscopy for health checkup. Therefore, those studies focused more on detecting small polyps.

Especially in the obstructive group, the sensitivity, specificity, and accuracy of virtual colonoscopic polyp detection were lower than they were in the nonobstructive group. This may be because of residual fecal material due to insufficient bowel preparation. Also, it may have originated from the limitation of our study. In the obstructive colorectal cancer group, the timing between preoperative virtual colonoscopy and postoperative colonoscopy differed by about 6 months. Even though the polyp detection rate was low in our study, a meaningful note is that the detection rate of proximal synchronous colorectal cancer was about $15 \%$ in patients with obstructive colorectal cancer.

In conclusion, virtual colonoscopy alone is a limited imaging tool for detecting proximal colon polyps. However, in patients with obstructive colorectal cancer, its use may have a limited benefit in detecting proximal synchronous colorectal cancer.

\section{CONFLICT OF INTEREST}

No potential conflict of interest relevant to this article was reported.

\section{REFERENCES}

1. Imperiale TF, Wagner DR, Lin CY, Larkin GN, Rogge JD, Ransohoff DF. Risk of advanced proximal neoplasms in asymptomatic adults according to the distal colorectal findings. N Engl J Med 2000;343:169-74.

2. Cone MM, Beck DE, Hicks TE, Rea JD, Whitlow CB, Vargas HD, et al. Timing of colonoscopy after resection for colorectal cancer: are we looking too soon? Dis Colon Rectum 2013;56:1233-6.

3. Lee KH, Kim HC, Yu CS, Myung SJ, Yang SG, Kim JC. Colonoscopic surveillance after curative resection for colorectal cancer with synchronous adenoma. Korean J Gastroenterol 2005;46:3817.

4. Ueno H, Mochizuki H, Hatsuse K, Hase K, Yamamoto T. Indicators for treatment strategies of colorectal liver metastases. Ann Surg 2000;231:59-66.

5. Choe EK, Park KJ, Chung SJ, Moon SH, Ryoo SB, Oh HK. Colonoscopic surveillance after colorectal cancer resection: who needs more intensive follow-up? Digestion 2015;91:142-9.

6. John SK, Robinson SM, Rehman S, Harrison B, Vallance A, French JJ, et al. Prognostic factors and survival after resection of colorectal liver metastasis in the era of preoperative chemotherapy: an 11-year single-centre study. Dig Surg 2013;30:293-301.

7. Missiaglia E, Jacobs B, D’Ario G, Di Narzo AF, Soneson C, Budinska E, et al. Distal and proximal colon cancers differ in terms of molecular, pathological, and clinical features. Ann Oncol 2014;25: 1995-2001.

8. Schoen RE, Gerber LD, Margulies C. The pathologic measurement of polyp size is preferable to the endoscopic estimate. Gastrointest Endosc 1997;46:492-6.

9. Chuang SC, Su YC, Lu CY, Hsu HT, Sun LC, Shih YL, et al. Risk factors for the development of metachronous liver metastasis in colorectal cancer patients after curative resection. World J Surg 2011;35:424-9.

10. National Foundation for Infectious Diseases (U.S.). 1-800-HEPB-873: get the facts: then get the vax. Bethesda (MD): National Foundation for Infectious Diseases; [19--].

11. Carlsson G, Petrelli NJ, Nava H, Herrera L, Mittelman A. The value of colonoscopic surveillance after curative resection for colorectal cancer or synchronous adenomatous polyps. Arch Surg 1987;122:1261-3.

12. Langevin JM, Nivatvongs S. The true incidence of synchronous cancer of the large bowel. A prospective study. Am J Surg 1984; 147:330-3. 